\title{
Influence of first and second premolar extraction or non-extraction treatments on mandibular third molar angulation and position. A comparative study
}

\author{
Beatriz Tarazona ${ }^{1}$, Vanessa Paredes ${ }^{2}$, Jose-Maria Llamas ${ }^{3}$, Rosa Cibrián ${ }^{4}$, Jose-Luis Gandia ${ }^{5}$
}

\author{
${ }^{1}$ MD. DDS in Dentistry. Undergraduate student inOrthodontics. Faculty of Medicine and Dentistry, University of Valencia, \\ Spain \\ ${ }^{2} \mathrm{PhD}$ in Dentistry. MS in orthodontics. Doctor Professor. Department of Orthodontics. Faculty of Medicine and Dentistry, Uni- \\ versity of Valencia, Spain \\ ${ }^{3}$ MS in orthodontics. Associate Professor. Orthodontist. Faculty of Dentistry, University of Seville, Spain \\ ${ }^{4}$ Professor. Department of Physiology. Faculty of Medicine and Dentistry, University of Valencia, Spain \\ ${ }^{5}$ Director of Postgraduate Orthodontics Masters Course. Department of Orthodontics. Faculty of Medicine and Dentistry, Uni- \\ versity of Valencia, Spain
}

\section{Correspondence:}

Unidad Docente de Ortodoncia

Departamento de Estomatología

Clínica Odontológica

Gasco Oliag 1

Valencia 46010 (Spain)

vanessa_paredes@yahoo.es

Tarazona B, Paredes V, Llamas JM, Cibrian R, Gandía JL. Influence of first and second premolar extraction or non-extraction treatments on mandibular third molar angulation and position. A comparative study. Med Oral Patol Oral Cir Bucal. 2010 Sep 1;15 (5):e760-6.

http://www.medicinaoral.com/medoralfree01/v15i5/medoralv15i5p760.pdf

Received: 14/10/2009

Accepted: 22/01/2010

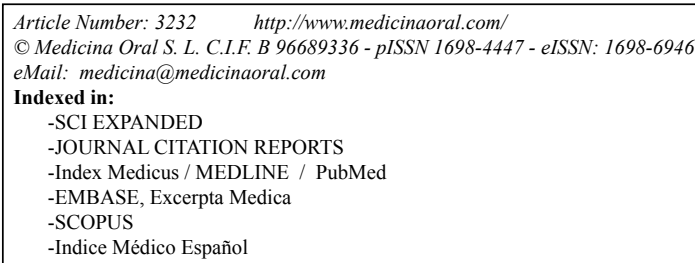

\begin{abstract}
The mandibular third molar $(3 \mathrm{M})$ is the tooth that is most often impacted, with lack of space being one of the reasons. In some orthodontic treatments, premolars are extracted in order to create space. The aims of our study are: firstly, to assess the changes in the angulation and position of the $3 \mathrm{M}$ in cases treated either with or without extraction of the first or second premolars; secondly, to analyse the variation in the gonial angle and the degree of inclusion of the $3 \mathrm{M}$; and lastly, to establish a predictive impaction model for $3 \mathrm{M}$. This study included 88 patients: 28 patients treated with extractions of first premolars, 30 with second premolars and 30 without.

The initial and final orthopantomography was analysed and the angulation of the $3 \mathrm{M}$ was measured, a new variable being created to determine the degree of $3 \mathrm{M}$ inclusion in the mandibular ramus. The results show that the angulation of $3 \mathrm{M}$ improves with time, regardless of treatment, and presents a greater disinclusion in cases treated with extractions. The gonial angle tends to diminish with age in all cases. The conclusions suggest that other factors may influence the angulation and position of $3 \mathrm{M}$ and that it is not possible to establish a predictive impaction model.
\end{abstract}

Key words: Mandibular third molar, premolar extraction. 


\section{Introduction}

The eruption of the mandibular third molar (M3) continues to be a subject of controversy that interests various specialisms of Odontology. Clinically its eruption is uncertain given that we do not know if there will be enough space for it to take up its correct position in the dental arch.

The mandibular third molar begins its development in the mandibular ramus with its occlusal surface directed upwards and forwards. To achieve a normal occlusal relationship, it has to undertake a straightening out movement to a greater or lesser degree, depending on its initial angle to the mandibular plane. Studies on the changes in the angulation of the mandibular third molar (1-4) show that it undergoes the straightening out process between 10 and 21 years of age, although this varies greatly depending on individuals, an increase in its mesial inclination being observed in some cases.

The development and eruption of the third molar presents varies greatly. It normally begins its development at about 8-9 years of age, but can occur between 5 and 14 years of age (5-7), and emerges in the oral cavity at around 18-24 years of age, although just as with its development, this can vary considerably $(6,8-11)$.

The third molar is the tooth that is most often impacted, impaction being more frequent in the mandibula than in the maxilla, varying between $9.5 \%$ and $39 \%(9-12)$, and may increase in patients who have been orthodontically treated to up to $50 \%$ (12). This variation is due to the different populations studied, to differences in the definition of the term "impaction", and to the different ages of the subjects on whom studies were undertaken.

Most authors agree that the main cause of impaction of the mandibular third molar is the lack of space available for its eruption $(8,12-15)$.

There are various factors described in the literature which appear to contribute, to a greater or lesser extent, to this lack of space:

- Alteration in the longitudinal growth of the mandible (1).

- Vertical direction of condyloid growth, associated with a decrease in bone resorption of the anterior border of the mandibular ramus (2-3).

- Distal eruption pattern of teeth (11).

- Greater size of mandibular third molar crowns in cases of impaction $(15,16)$. (although these differences were not significant).

- Delays in development of facial structure (9).

Some studies in the literature associate extractionist therapy with a mesialization of the mandibular molars (17-19) and with an increase in the retromolar space (13, 17-22), whereas the non-extractionist associates extraction with a significant increase in the frequency of mandibular third molar impaction (22) and a reduction in its eruption $(14,18)$, although there are others who find very little difference between subjects treated with or without extractions (14).
The aims of this study are therefore:

1. To assess the changes that take place in the angulation and position of the mandibular third molar over time in patients treated with extraction of the mandibular first and second premolars and to compare the results with patients treated without extractions.

2. To analyse the variation of the gonial angle and the degree of inclusion of the mandibular third molar, depending on age and the treatment undertaken.

3. To establish a predictive impaction model for the mandibular third molar, analysing whether the initial angulation of the third molar has an influence on the decision to carry out extractions or not.

\section{Materials and Methods}

A sample was selected of 88 patients ( 32 males and 56 females) who attended various orthodontic offices in the cities of Valencia and Seville (Spain). Of this sample, 28 patients (10 males and 18 females) had been treated with first premolar extractions, 30 with second premolar extractions (10 males and 20 females) and the remainder, 30 patients (12 males and 18 females) without extractions.

The initial mean age of the sample was 13.24 and at the end 17.1 years. All patients presented different Angle types and had been treated with fixed appliances.

The mean age of the patients as regards sex and the treatment undertaken is shown in (Table 1).

The inclusion criteria were:

- All patients had to have an orthopantomography before the beginning of Orthodontic treatment (T1) and at the end of the same (T2).

- All patients had to have the crown of the mandibular third molar formed at the time of beginning Orthodontic treatment.

- The orthopantomographs had to be of good quality without distortions or magnifications.

All the orthopantomographs were digitalised using a conventional scanner and the Rhinoceros ${ }^{\odot} 3.0$ program was used to trace and calculate the different variables

Table 1. Mean age of the patients as regards sex and the treatment undertaken.

\begin{tabular}{|c|c|c|c|}
\hline SEX & TREATMENT & Mean & SD \\
\hline \multirow{2}{*}{$\sum_{\substack{z \\
z}}^{Z}$} & Non-extraction & 12.85 & 0.66 \\
\cline { 2 - 4 } & First premolar extraction & 13.82 & 0.64 \\
\cline { 2 - 4 } & Second premolar extraction & 13.43 & 0.62 \\
\hline \multirow{2}{*}{$\sum_{y}^{z}$} & Non-extraction & 12.3 & 0.81 \\
\cline { 2 - 4 } & First premolar extraction & 13.14 & 0.93 \\
\cline { 2 - 4 } & Second premolar extraction & 13.66 & 0.89 \\
\hline
\end{tabular}




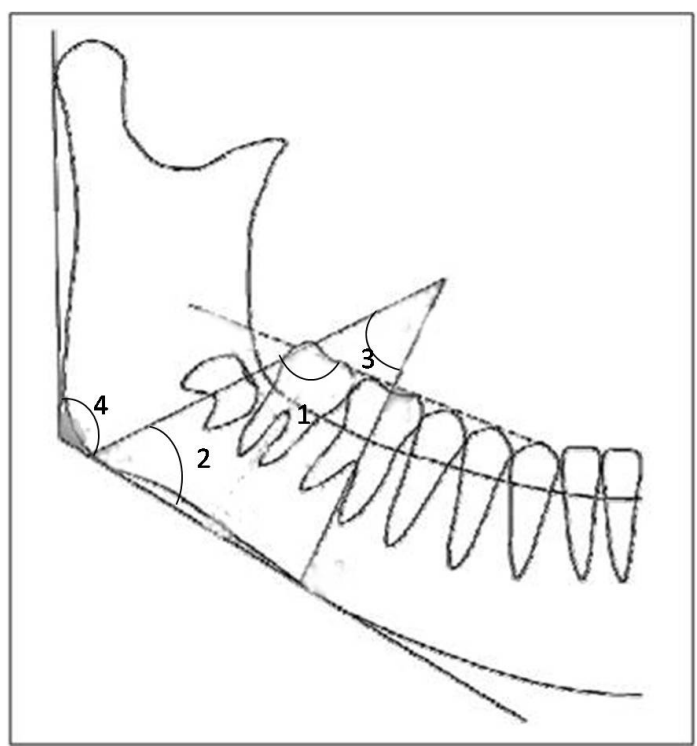

Fig. 1. Determination of Angular variables: (1) M3-OP; (2) M3-MP; (3) M1-M3; (4) GA.

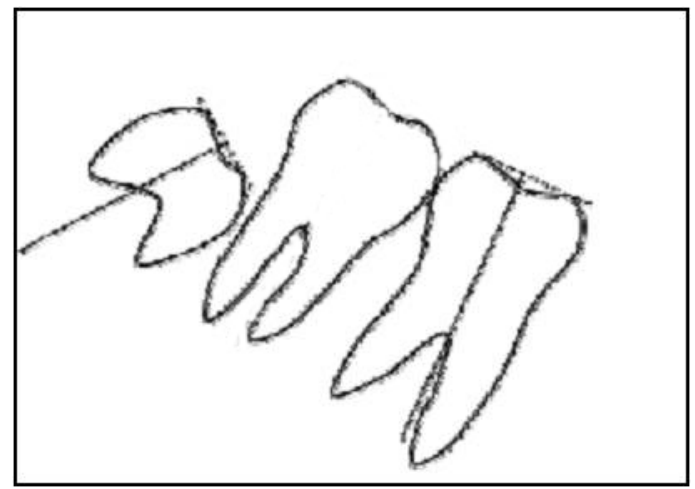

Fig. 2. Determination of longitudinal axis of the mandibular molars.

employed in this study. All measurements were taken by the same operator.

To undertake our study, four angular variables, (as can be observed in (Fig. 1), and one linear variable -the percentage of inclusion in the ramus whose quantification is detailed later on- were measured.

1. Longitudinal angle axis of the mandibular third molar (M3) to the occlusal plane (OP): M3-OP.

This is the angle formed by the longitudinal axis of the mandibular third molar to the occlusal plane. The occlusal plane is defined by the cuspids of the first molar and the second mandibular premolar. In those cases in which the second premolar still had not erupted, the occlusal plane was considered to be that which passed through the mandibular second temporary molar.

The longitudinal axis of the mandibular third molar runs perpendicular to the line that joins one of the mesial and distal cuspids of the molar, as can be observed in (Fig. 2).
2. The longitudinal axis angle of the mandibular third molar (M3) to the mandibular plane (MP): M3-MP.

This is the angle formed by the longitudinal axis of the mandibular third molar to the mandibular plane. The mandibular plane is the tangential line to the two lowest points of the anterior and posterior borders of the mandibula. The longitudinal axis of the mandibular third molar is constituted in the same way as in the above variable.

3. The longitudinal axis angle of the mandibular first molar (M1) to the longitudinal axis of the mandibular third molar (M3): M1-M3.

This is the angle formed between the longitudinal angle of the first and third mandibular molars. The angle has negative values when the longitudinal angles of the molars diverge towards occlusal, i.e. there is a distal or straightening inclination, and positive values when they converge towards occlusal, i.e., when there is a mesial inclination.

4. Gonial angle: GA.

This is the inner angle formed by the tangent to the two lowest points of the mandibular body and the tangent to the backmost points of the mandibular ramus.

5. Degree of mandibular third molar (M3) inclusion in the mandibular ramus(MR): M3-MR.

To assess the degree of M3 inclusion in the mandibular ramus, a reference line is traced perpendicular to the line that joins the two lowest points of the sigmoidal notch, which passes through the backmost point of the anterior border of the mandibular ramus, as shown in (Fig. 3A).

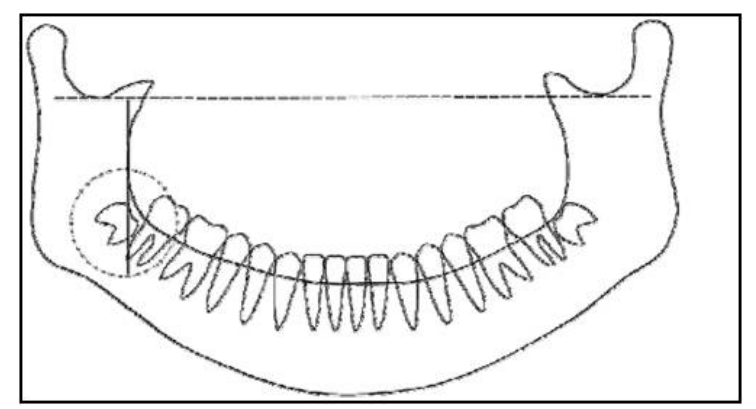

Fig. 3A. Degree of mandibular third molar inclusion in the mandibular ramus.

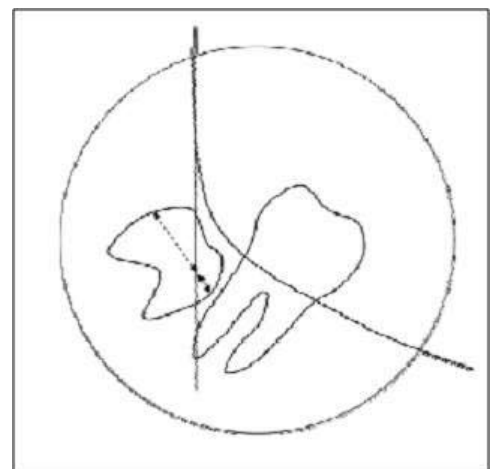

Fig. 3B. Fig. 3A in detail. Degree of inclusion of the mandibular third molar. 
Table 2. Intraobserver error of the four angular and one linear variable.

\begin{tabular}{|c|c|c|c|c|}
\hline VARIABLES & MEAN & TD & $\mathbf{9 5 \%}$ CI & $\begin{array}{c}\text { SIG. } \\
\text { (BILATERAL) }\end{array}$ \\
\hline M3-OP & 0.57 & 3.90 & $-1.59-2.73$ & 0.58 \\
\hline M3-MP & -0.97 & 3.99 & $-3.18-1.23$ & 0.36 \\
\hline M1-M3 & 0.92 & 2.67 & $-0.56-2.40$ & 0.20 \\
\hline GA & -0.71 & 1.87 & $-1.74-0.33$ & 0.16 \\
\hline 3M-MR & -0.01 & 0.04 & $-0.03-0.02$ & 0.54 \\
\hline
\end{tabular}

The percentage of M3 that is found per distal of that perpendicular line, with respect to total width (Fig. 3B), measures the degree of inclusion.

The data gathered was stored and analysed using the SPSS v. 15.0 statistical analysis program. The range, mean, typical deviation (TD) and the confidence interval (CI) of $95 \%$ of the mean of each magnitude studied and at the two moments of study, before and after treatment, were determined.

Mean comparison tests of two paired and non-paired samples (t-Student), depending on cases, and of 3 samples (ANOVA), using the Scheffé test for multiple comparisons, were used. The proportion comparison test was also used.

The method's intraobserver error was found by analysing $10 \mathrm{x}$-rays, chosen at random, of each of the three treatment groups for a second time. (Table 2) shows the great repeatability of the measurements.

\section{Results}

The results of the four angular variables are shown in (Table 3).

Changes in the angulation and position of the mandibular third molar.

The angle of the mandibular third molar to the occlusal plane (M3-OP) decreases; to the mandibular plane (M3-MP) increases; and to the axis of the mandibular first molar (M3-M1) decreases, in all patients, with a statistically significant difference between the initial and final values. However, we have not found significant differences in terms of the value of those variations when we compared the three types of treatment: cases treated with extractions of first or second premolars or without extractions.

Changes in the gonial angle.

Considering all the cases as a whole, the gonial angle diminishes over time by a mean of $1.42^{\circ}$ in the three groups, the statistically significant variation being $(p<0.05)$. On analysing the variation, depending on the treatment undertaken, we found that the greatest reduction in the gonial angle takes place in cases of second premolar extractions ands non-extractions, the differences being statistically significant for these two groups.

Table 3. Comparation of the results of the four angular variables before (T1) and after treatment (T2) in the three different treatments. T1-T2 column represents initial and final differences. Positive values mean a reduction while negative ones an increase in the variable. $\left.{ }^{*}\right)$ Means results being statistically significant $(\mathrm{P}<0,05)$.

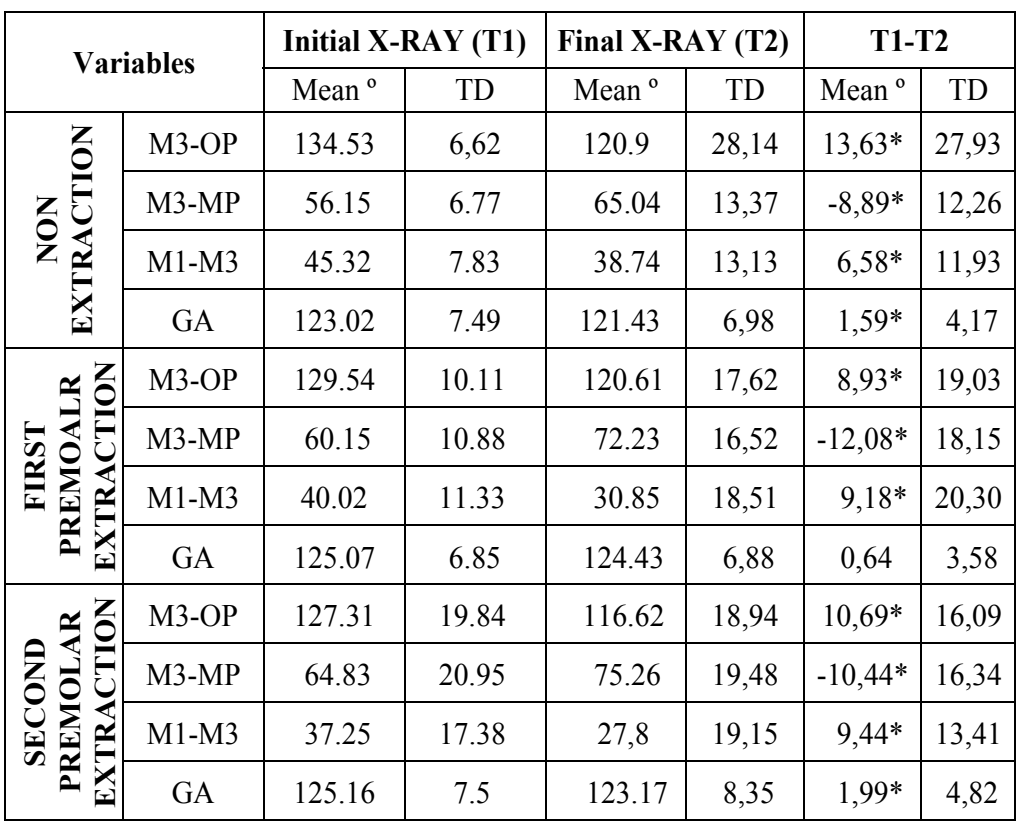




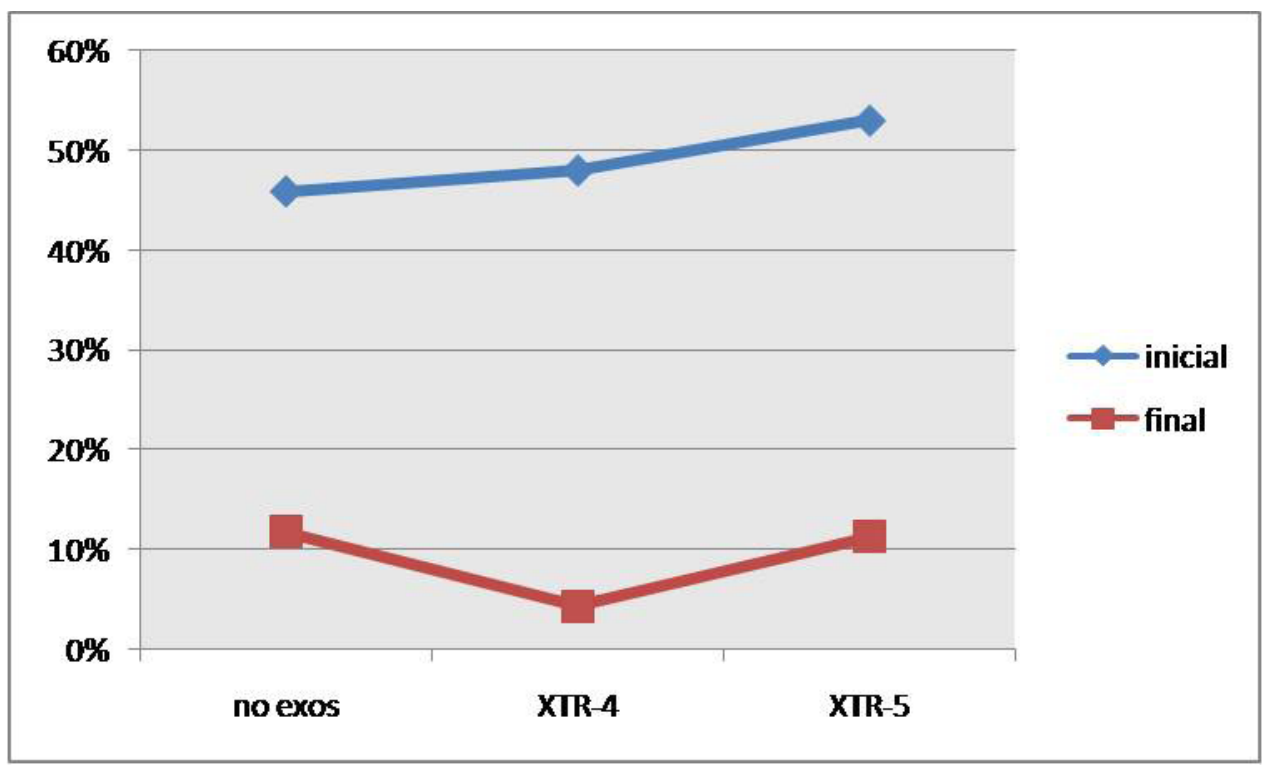

Fig. 4. Degree (\%) of initial (T1) and final (T2) disinclusion of the mandibular third molar in the three different treatments.

Table 4. Initial inclusión (T1) and final inclusión (T2) in different orthodontic treatment.

\begin{tabular}{|c|c|c|c|c|c|c|c|c|c|}
\hline \multirow{2}{*}{ INCLUSION 3M } & \multicolumn{3}{|c|}{ NON EXTRACTION } & \multicolumn{3}{c|}{$\begin{array}{c}\text { FIRST PREMOLAR } \\
\text { EXTRACTION }\end{array}$} & \multicolumn{3}{c|}{$\begin{array}{c}\text { SECOND PREMOLAR } \\
\text { EXTRACTION }\end{array}$} \\
\cline { 2 - 10 } & $\mathrm{T} 1$ & $\mathrm{~T} 2$ & $\mathrm{~T} 2-\mathrm{T} 1$ & $\mathrm{~T} 1$ & $\mathrm{~T} 2$ & $\mathrm{~T} 2-\mathrm{T} 1$ & $\mathrm{~T} 1$ & $\mathrm{~T} 2$ & $\mathrm{~T} 2-\mathrm{T} 1$ \\
\hline Means & $45.9 \%$ & $11.8 \%$ & $34.1 \%$ & $48 \%$ & $4.4 \%$ & $43.6 \%$ & $53 \%$ & $11.2 \%$ & $41.8 \%$ \\
\hline
\end{tabular}

Degree of mandibular third molar inclusion.

The results for the single linear measurement are shown in (Table 4) and represented in (Fig. 4) and indicate the degree of disinclusion that the mandibular third molar suffers with age. This reduction was of $34.1 \%$ in cases without extractions, $43.6 \%$ and $41.8 \%$ in cases of first and second premolar extractions respectively, there being no statistically significant differences between them.

\section{Discussion}

The study of the mandibular third molar has always aroused great interest in clinical practice. Normally, studies on the third molar has centred on investigating the effects that the eruption of it has on dental arches, but not on observing the changes that orthodontic treatments, with or without extractions, cause in the position and angulation of that molar.

Studies that do appear in the literature on these changes are difficult to compare, as the material and methods used vary.

Due to the fact that the mean age of our sample at the end of the treatment was 17.1 years old, the eruption or final impaction of the mandibular third molar could not be fully evaluated. However, we have been able to de- termine the changes that have taken place in the inclination of the molar in patients treated with or without extractions of the first or second premolars.

Authors such as Ricketts (23) suggest that the probability of mandibular third molar eruption is directly related to the percentage of that molar found in front of the anterior border of the mandibular ramus, in such a way that, for a favourable eruption prognosis, half of the crown should be in front of the anterior border of the ramus. In contrast, other authors such as Kim et al. (6) suggest that the space for the correct eruption of the mandibular third molar could be less than that previously observed by Ricketts (23).

Changes in the angulation and position of the mandibular third molar.

The three angular measurements confirm that the mandibular third molar improves its inclination over time, regardless of the treatment undertaken. We, therefore, have not been able to show that the mandibular third molar improves its inclination in patients treated with extractions. Our results coincide with those obtained by Haavikko et al. (24) who claims that extractions of mandibular premolars accelerated, but did not favour, the eruption of the mandibular third molars. Nevertheless, other authors such as Richardson et al. (5), Kim et al. (6) 
or Jain et al. (25), observed that the extraction of premolars made more space in the molar area and, therefore, improved the angulation of the mandibular third molar compared to patients treated without extractions.

Changes in the gonial angle.

The reduction of the gonial angle from the initial and to the final value, found in all three groups of patients in our study, coincides with other authors such as Altonen et al. (13) or Thompson et al. (26) who claimed that there was a tendency for the gonial angle to diminish with age. We have not found any statistically significant difference in the reduction of the gonial angle due to extractions of first premolars.

Observing the absolute value of the difference between the initial and final gonial angle in the cases treated with first premolar extractions $\left(\mathrm{T} 1-\mathrm{T} 2=0.64^{\circ}\right)$, second premolar extractions $\left(\mathrm{T} 1-\mathrm{T} 2=1.99^{\circ}\right)$ and without extractions $\left(\mathrm{T} 1-\mathrm{T} 2=1.59^{\circ}\right)$, we can observe how the greatest reduction occurs in the cases of second premolar extraction and in cases without extractions.

If we take the patients treated with second premolar extractions, the result coincides with that observed by Björk A (27), who claimed that patients treated with extractions presented greater resorption of the anterior border of the ramus and consequently there would be more space for the eruption of the mandibular third molar.

Degree mandibular third molar inclusion

In our study, on observing the evolution of mandibular third molar impaction between $\mathrm{T} 2$ and $\mathrm{T} 1$, we noted that there is a reduction in the disinclusion of the mandibular third molar in the mandibular ramus between the two moments of study in all cases and a tendency for the mandibular third molar to straighten out. Cases treated without extractions obtain a lower disinclusion percentage (34.1\%) than cases treated with first premolar extractions (43.6\%) and second premolar extractions $(41.8 \%)$, but without there being a statistically significant difference between them $(\mathrm{P}<0.04)$.

If the reduction of impaction were due to changes produced in the longitudinal axis of the mandibular third molar, one would expect to find the same disinclusion both in cases treated with or without extractions. However, we have found greater disinclusion in cases treated with extraction although without reaching statistical significance. Other factors such as mesial displacement of the mandibular third molar could explain the greater disinclusion of it in cases treated with extractions.

From our results we cannot affirm that treatments with extraction of both first and second premolars favour the eruption of the mandibular third molar. The results of this study suggest that other factors, besides premolar extraction, may have an influence on the change in angulation and the position of the mandibular third molar.
It is not possible to determine a predictive model for the future decision on whether to undertake an extraction or not at the age of 13 according to the results of this study: to do so, a longitudinal follow-up on these patients over more years would be required.

\section{Conclusions}

The conclusions of this study are that:

1. The angulation of the mandibular third molar improves over time, regardless of whether the orthodontic treatment is undertaken with extractions or not.

2. The gonial angle tends to diminish with age in all cases without there being statistically significant differences between groups.

3. The mandibular third molar suffers greater disinclusion in the ascending ramus of the mandibula with age in cases treated with extractions. This could be due to other factors such as the increase in space caused by mesialization on undertaking extractions or resorption of the anterior border of the mandibular ramus.

4. With the results of this study, it is not possible to determine a predictive model for a future decision on whether to undertake extractions or not at the age of 13 years old.

\section{References}

1. Sandhu S, Kaur T. Radiographic evaluation of the status of third molars in the Asian-Indian students. J Oral Maxillofac Surg. 2005;63:640-5.

2. Ay S, Agar U, Biçakçi AA, Köşger HH. Changes in mandibular third molar angle and position after unilateral mandibular first molar extraction. Am J Orthod Dentofacial Orthop. 2006;129:36-41.

3. Silling G. Development and eruption of the mandibular third molar and its response to orthodontic therapy. Angle Orthod. 1973;43:271-8.

4. Salehi P, Danaie SM. Lower third molar eruption following orthodontic treatment. East Mediterr Health J. 2008;14:1452-8.

5. Richardson ME, Dent M. Some aspects of lower third molar eruption. Angle Orthod. 1974;44:141-5.

6. Kim TW, Artun J, Behbehani F, Artese F. Prevalence of third molar impaction in orthodontic patients treated nonextraction and with extraction of 4 premolars. Am J Orthod Dentofacial Orthop. 2003;123:138-45.

7. Kaplan RG. Some factors related to mandibular third molar impaction. Angle Orthod. 1975;45:153-8.

8. Artun J, Thalib L, Little RM. Third molar angulation during and after treatment of adolescent orthodontic patients. Eur J Orthod. 2005;27:590-6.

9. Yavuz I, Baydaş B, Ikbal A, Dağsuyu IM, Ceylan I. Effects of early loss of permanent first molars on the development of third molars. Am J Orthod Dentofacial Orthop. 2006;130:634-8.

10. Elsey MJ, Rock WP. Influence of orthodontic treatment on development of third molars. Br J Oral Maxillofac Surg. 2000;38:350-3.

11. Staggers JA, Germane N, Fortson WM. A comparison of the effects of first premolar extractions on third molar angulation. Angle Orthod. 1992;62:135-8.

12. Richardson ME. The early developmental position of the lower third molar relative to certain jaw dimensions. Angle Orthod. 1970;40:226-30.

13. Altonen M, Haavikko K, Mattila K. Developmental position of lower third molar in relation to gonial angle and lower second molar. Angle Orthod. 1977;47:249-55. 
14. Hattab FN. Positional changes and eruption of impacted mandibular third molars in young adults. A radiographic 4-year follow-up study. Oral Surg Oral Med Oral Pathol Oral Radiol Endod. 1997;84:604-8.

15. Richardson ME. Development of the lower third molar from 10 to 15 years. Angle Orthod. 1973;43:191-3.

16. Richardson M. Changes in lower third molar position in the young adult. Am J Orthod Dentofacial Orthop. 1992;102:320-7.

17. Richardson M. Pre-eruptive movements of the mandibular third molar. Angle Orthod. 1978;48:187-93.

18. Richardson ME. Lower third molar space. Angle Orthod. 1987;57:155-61.

19. Efstratiadis SS, Kent RL Jr, Lebret LM, Moorrees CF. Spatial position of mandibular third molars in monozygotic twins. Angle Orthod. 1984;54:271-82.

20. Richardson ER, Malhotra SK, Semenya K. Longitudinal study of three views of mandibular third molar eruption in males. Am J Orthod. 1984;86:119-29.

21. Bayram M, Ozer M, Arici S. Effects of first molar extraction on third molar angulation and eruption space. Oral Surg Oral Med Oral Pathol Oral Radiol Endod. 2009;107:e14-20.

22. De-la-Rosa-Gay C, Valmaseda-Castellón E, Gay-Escoda C. Spontaneous third-molar eruption after second-molar extraction in orthodontic patients. Am J Orthod Dentofacial Orthop. 2006;129:337-44.

23. Ricketts RM. A principle of arcial growth of the mandible. Angle Orthod. 1972;42:368-86.

24. Haavikko K, Altonen M, Mattila K. Predicting angulational development and eruption of the lower third molar. Angle Orthod. 1978;48:39-48.

25. Jain S, Valiathan A. Influence of first premolar extraction on mandibular third molar angulation. Angle Orthod. 2009;79:1143-8.

26. Thompson GW, Popovich F. Static and dynamic analyses of gonial angle size. Angle Orthod. 1974;44:227-34.

27. Bjork A. Variations in the growth pattern of the human mandible: longitudinal radiographic study by the implant method. J Dent Res. 1963;42Pt 2:400-11. 